\title{
A Review of Power Electronics Based Microgrids
}

\author{
Xiongfei Wang ${ }^{\dagger}$, Josep M. Guerrero*,**, Frede Blaabjerg*, and Zhe Chen* \\ $\dagger *$ Dept. of Energy Technology, Aalborg University, Aalborg, Denmark \\ ** Dept. of Automatic Control Systems and Computer Engineering, Technical University of Catalonia, Barcelona, Spain
}

\begin{abstract}
The increased penetration of Distributed Energy Resources (DER) is challenging the entire architecture of conventional electrical power system. Microgrid paradigm, featuring higher flexibility and reliability, becomes an attractive candidate for the future power grid. In this paper, an overview of microgrid configurations is given. Then, possible structure options and control methods of DER units are presented, which is followed by the descriptions of system controls and power management strategies for AC microgrids. Finally, future trends of microgrids are discussed pointing out how this concept can be a key to achieve a more intelligent and flexible power system.
\end{abstract}

Key Words: AC microgrids, Distributed energy resources, Load sharing, Power converters

\section{INTRODUCTION}

Liberalized electricity market, environmental concerns with greenhouse gas emissions, energy efficiency, and diversified energy sources constitute the most important driving forces for the proliferation of Distributed Energy Resources (DER) in the electrical power system. With the growing deployment of DER units, especially small-scale Combined Heat and Power (CHP) plants and Renewable Energy Sources (RES) based Distributed Generation (DG) units, distribution systems can no longer be considered as passive networks [1]. The entire architecture of future electrical power system must be redesigned to undertake the increasingly complex operations. As a consequence, three possible concept models are envisioned: Microgrids, Active Networks supported by ICT and the 'Internet' model [2].

Microgrid paradigm interconnects multiple customers to multiple DER units including DG and Distributed Storage (DS) units, and can form an intentional or non-intentional energetic island in the distribution network. In the context of microgrid, customers and DER units not only can operate in parallel with the main grid, but requires also a smooth transition to the intentional or non-intentional islanding modes during abnormal grid conditions. In contrast to conventional distribution systems, this kind of grid structure has much more flexibilities on the control of DER units, consequently offering potential benefits of better power quality, more reliable electric service and dispatchable local power, as well as higher power supply efficiency through the optimally located micro CHP units [3]. Extensive research on microgrids and a number of

Manuscript received Feb. 5, 2011; revised Nov. 24, 2011

Recommended for publication by Associate Editor Seung-Ho Song.

$\dagger$ Corresponding Author: xwa@et.aau.dk

Tel: +45-2136-9166, Fax: +45-9815-1411, Aalborg University

* Dept. of Energy Technology, Aalborg University University, Denmark

** Dept. of Automatic Control Systems and Computer Engineering, Technical

University of Catalonia, Spain worldwide demonstration projects, e.g. CERTS microgrid in US, Hydro-Quebec microgrid in Canada, NEDO microgrid in Japan, and EU Microgrid in Europe, have shown challenges and solutions in the microgrid field [3]-[5].

In recent years, power electronics technology experiences a rapid development, thanks to the fast evolution of power semiconductors that improves the transient response of the power stage, and Digital Signal Processors (DSP) being able to reduce the processing time and increase the complexity of the control algorithms. A wide spread use of power electronic converters in DER units not only furnishes cost-effective and flexible DER interfaces to the networks, but enables also microgrids to control and manage the power and energy flows efficiently [6]-[9]. Furthermore, with the help of the Flexible AC Transmission Systems (FACTS) devices at lower voltage levels, novel microgrid configurations and operational scenarios have been proposed for some specific applications [10], [11].

This paper shows an overview on the configurations and the control strategies for power electronics based microgrids. The paper is organized as following. Section II gives a brief review of microgrid configurations with respect to the form of power transmission and distribution within a microgrid. Various structures of power electronics interfaced DER units in AC microgrids are described in Section III, which is followed by the discussion of control schemes for DER units. Section $\mathrm{V}$ discuss system controls and energy management strategies for AC microgrids. Finally, the conclusions and future trends of microgrids are presented in Section VI.

\section{MiCROGRID CONFIGURATIONS}

Fig. 1 shows a general configuration for power electronics based microgrids. Normally a microgrid consists of a static transfer switch (STS), distributed critical and noncritical loads, 


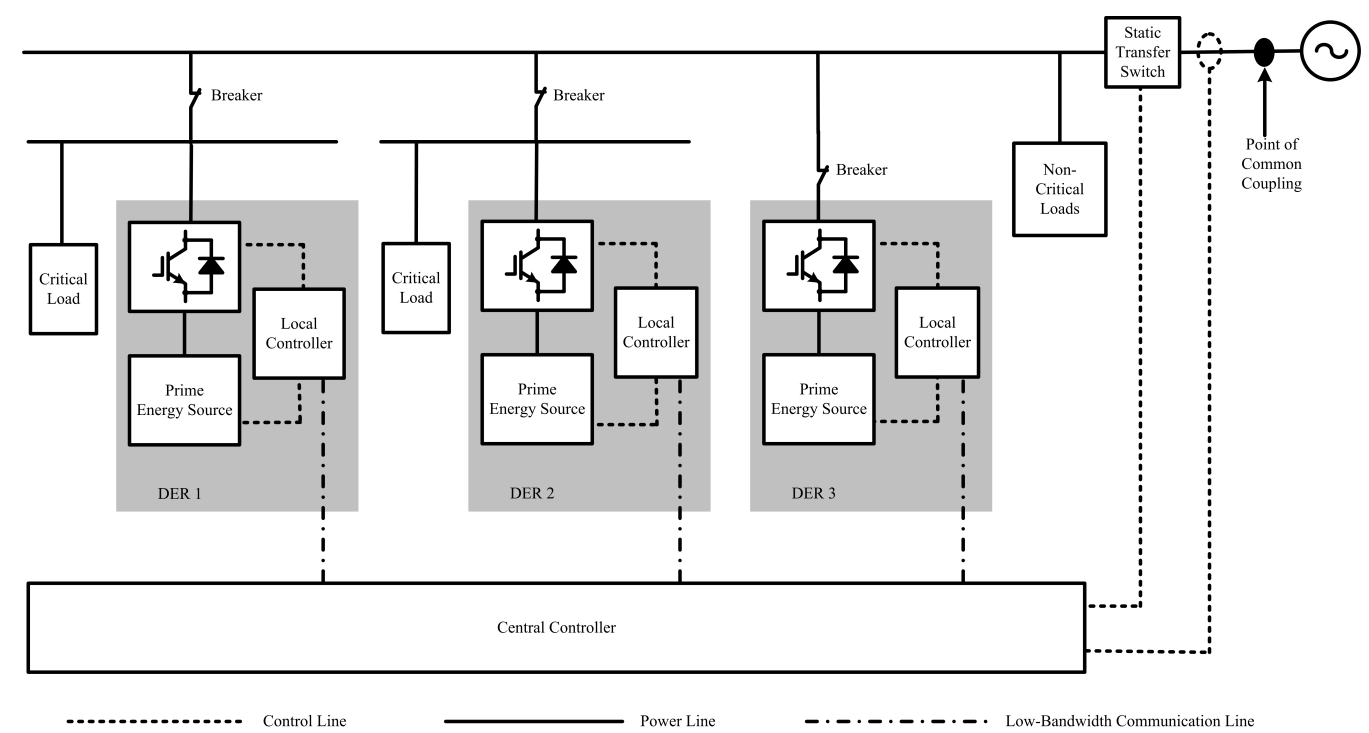

Fig. 1. General configuration for a power electronics based microgrid.

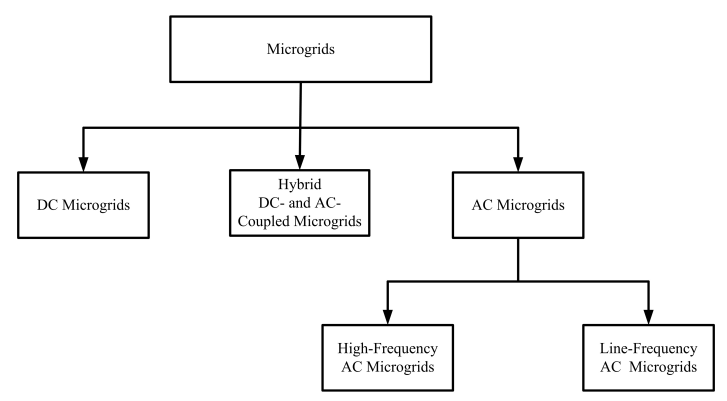

Fig. 2. Classification of power electronics based microgrids.

multiple DER units with various power electronics interfaces, protection devices, as well as measurement, monitoring, and control units. In [12], microgrid architectures are classified into three categories depending on their applications which are: i) utility microgrids, ii) industrial and commercial microgrids, and iii) remote microgrids. However, recent advances in power electronics and FACTS systems offer more options for microgrid configurations with different customer requirements.

Another classification of microgrid configurations can be done according to the way used to transmit and distribute the power by microgrids, as depicted in Fig. 2. This classification consists of: DC microgrids, High-Frequency AC (HFAC) microgrids, Line-Frequency AC (LFAC) microgrids, and hybrid DC- and AC-coupled microgrids.

\section{A. DC Microgrids}

DC distributed power systems have been widely applied in telecommunication systems [14], electric vehicles [15], and shipboard power systems [16]. Recently, the intensive use of electronic loads in office buildings and commercial facilities, together with the fast growing of Photovoltaic (PV) and fuel cell system, make Low-Voltage DC (LVDC) microgrid become an attractive network solution. For instance, an LVDC microgrid configuration is presented for commercial power system with sensitive electronic loads in [17].

Fig. 3 depicts a typical structure of power electronics based LVDC microgrids. Several research works have discussed the operation and control of dc microgrids, including system voltage controls [18], different operational scenarios, and the transitions between grid-connected and islanded modes [13], as well as DC microgrid protection schemes [19]. Moreover, the feasibility of a DC distribution network is analyzed systematically in [20]. It is concluded that if a proper voltage level is chosen, the LVDC microgrids can present superior performances to Low-Voltage AC (LVAC) microgrids in terms of cost and efficiency.

\section{B. HFAC Microgrids}

From long time ago, there are well established distributed power systems for military and aircraft systems working in single-phase $400 \mathrm{~Hz}$ [21]. It is well known that by increasing the frequency, the size and weight of the power electronics equipment can be reduced. However, the HFAC distributed power systems are limited to local areas, since the losses are dramatically increasing with the distance. Thus, this concept is only appropriate for small areas [22].

A paradigmatic example of a power electronics based HFAC microgrid can be found in [11], which is made up of a singlephase $500 \mathrm{~Hz}$ HFAC line, a Unified Power Quality Conditioner (UPQC), and a Universal Active Power Line Conditioner (UPLC), as shown in Fig. 4. The UPQC is used to compensate voltage distortions which result from nonlinear loads. The UPLC, interconnecting the HFAC link to the main grid, is adopted to control active and reactive power flows from/to the microgrid. It is obvious that two FACTS systems constitute the essential parts of microgrid power flow control, thus enabling the microgrid operate at a higher frequency $(400 \mathrm{~Hz}$ or 500 $\mathrm{Hz})$ power system applications. However, as stated earlier, the power losses and voltage drop increase with the line length and frequency in an HFAC system. Hence, these two factors must be taken into account when designing the size of a HFAC microgrid [21], [22]. 


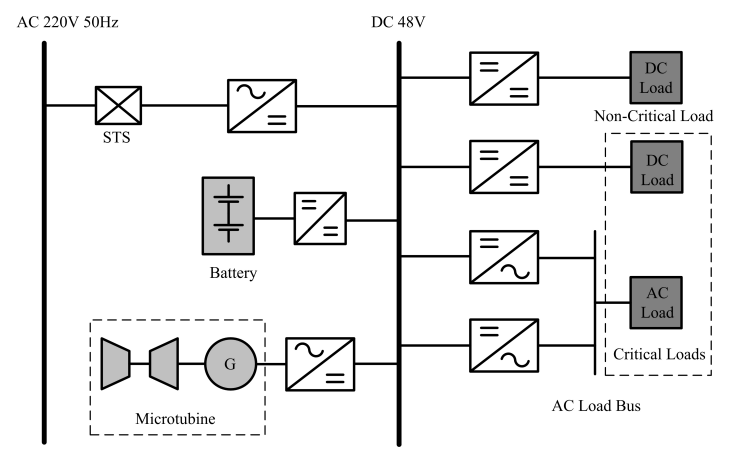

Fig. 3. Typical structure of a power electronics based LVDC microgrid.

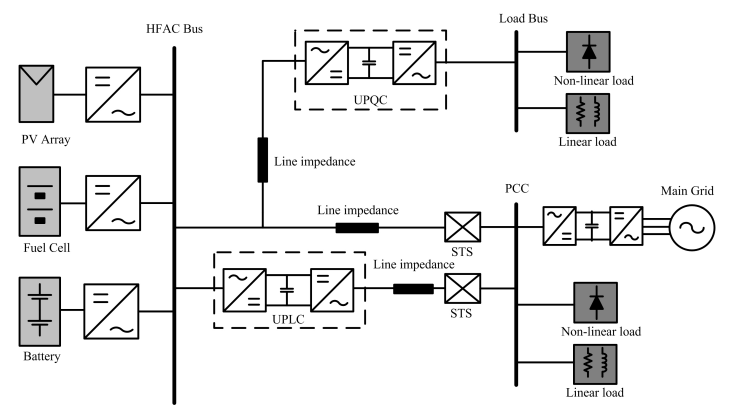

Fig. 4. Typical structure of a power electronics based HFAC microgrid [11].

\section{LFAC Microgrids}

LFAC microgrids have been the main research area since the microgrid concept was proposed. Fig. 5 depicts a typical configuration of power electronics based LFAC microgrids. A wide variety of LFAC microgrid concepts and operation scenarios can be found in the literature. Hence, a systematically review of the operation and controls of LFAC microgrids, including the structures and control schemes of DER units in LFAC microgrids, as well as the microgrid power and energy management strategies will be presented in the following sections.

\section{Hybrid DC- and AC-Coupled Microgrids}

The hierarchical microgrid architecture with DC and AC links has been presented in [23]-[25]. It aims to provide an effective way to integrate a variety of DER units into existing distribution system. Hybrid DC- and AC-coupled microgrids use the DC part for connecting the distributed energy storage systems including batteries, fuel cells and even flywheels connected to bidirectional AC-DC converters, and other DC energy sources like PV systems connected through DC-DC Boost converters and small turbines (gas and wind) connected through rectifiers. A decoupled control of DC and AC parts of microgrid is achieved by using power converters [25]. Although the hybrid DC- and AC-coupled microgrid concept provides a more flexible approach to integrate DER units, structures and operation scenarios, along with the stability and protection issues still need to be further investigated.

\section{Structures of ElectronicAlly-Coupled DER UNITS}

DER units within a microgrid can be distinguished by their interface characteristics as conventional rotary DG units

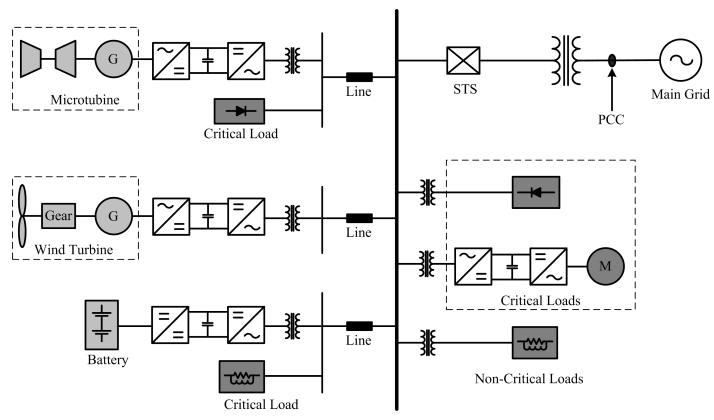

Fig. 5. Typical structure of a power electronics based LFAC microgrid.

and electronically-coupled DER units [26]. As the name implies, conventional rotary DG units interface to the microgrid through rotating generators, including fixed-speed wind turbines, reciprocating machines and small hydro turbines. In contrast, electronically-coupled DER units utilize power electronics converters to match their characteristics and the requirements of grid conditions. The electronically-coupled DER units involve variable-speed wind turbines and other RES based DG units, microturbines, Internal Combustion Engines (ICE), as well as various distributed storage units and plug-in vehicles.

Fig. 6 shows three commonly used wind turbine systems to separately represent the two groups of DER units, including Squirrel-Cage Induction Generator (SCIG) based fixed-speed wind turbines without using power electronics interfaces, Doubly-Fed Induction Generator (DFIG) based variable- speed wind turbines with partially rated power electronics interfaces, and Permanent Magnet Synchronous Generator (PMSG) based variable-speed wind turbines with full-scale power electronics interfaces [7], [8].

Power electronics interfaces have a number of superior performances over the rotating generators, such as higher efficiency, active harmonic filtering, and flexible control of active and reactive power flows. A wide variety of power electronic converter topologies are consequently proposed for interfacing DER units. As mentioned earlier, the power electronics based LFAC microgrids are the focus here, and therefore, the structures and controls for electrically-coupled DER units within AC microgrids will be discussed below.

\section{A. Structures of Electronically-Coupled DER Units}

Since prime energy sources can produce either DC or AC voltages, the general structure of electronically-coupled DER units consequently fall into two categories. For wind turbine, ICE, and microturbine generation systems, the outputs are either HFAC or LFAC voltages, whereas the Photovoltaic (PV), fuel cell power systems and battery systems produce DC voltages. The output voltages from those energy resources are then converted by means of a power electronics converter to the voltages that are compatible to the microgrid. Hence the type of output voltage from prime energy sources determines the topologies of power electronics interfaces.

Moreover, the expected operational scenario of a microgrid also imposes limitations when choosing the appropriate power stage topology. For example, in the CERTS microgrid, the plug-and-play feature requires that all DG units have a unified 


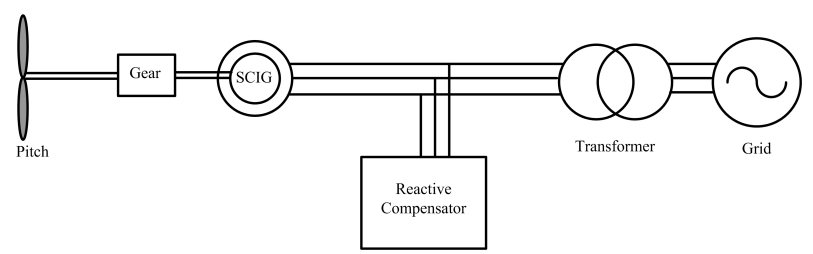

(a)

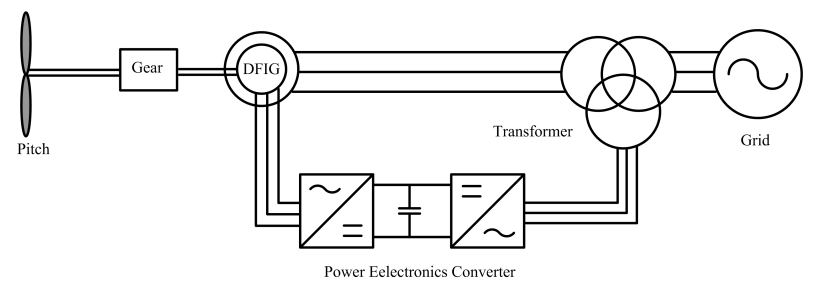

(b)

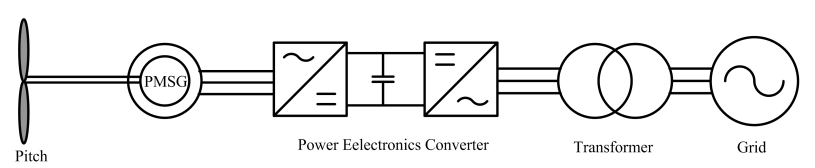

(c)

Fig. 6. Three commonly used wind turbine systems. (a) Fixed-speed wind turbine system without power electronics interface. (b) Variable wind turbine system with partial-scale power electronics interface. (c) Variable wind turbine system with full-scale power electronics interface.

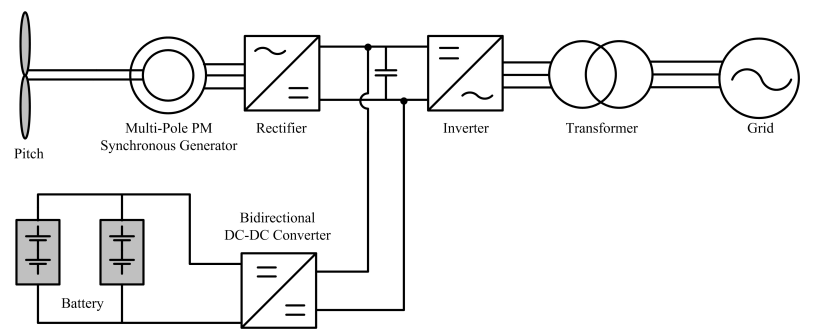

Fig. 7. Typical structure of a wind turbine system integrated with a battery storage unit.

dynamic performance regardless of prime energy source type [27]. This implies that an energy storage module with a bidirectional converter must be included within each DG unit.

Fig. 7 depicts a wind turbine integrated with a battery energy storage system. The bidirectional converter controls the operation of the storage unit based on the dynamics of the prime energy source [28]. The use of the intermediate storage energy system in the DC link allows programming virtual inertias and improving low voltage ride-through capabilities. Thus, the control system for grid-side inverter is decoupled from generator-side rectifier. Together with the droop functions for the grid-side inverter, virtual inertias can be integrated. Thus, the structures of electronically-coupled DER units are not just determined by the types of prime energy sources, but also dependent on the load requirements, microgrid structures and associated operational scenarios.

Comprehensive reviews of power converter topologies for DER units have been reported [7]-[9]. Those converters can be classified into two categories depending on the number of power processing stages, from the point of view of system structure.

1) Single-Stage Power Conversion Systems: Fig. 8 depicts the basic configuration of a single-stage power conversion

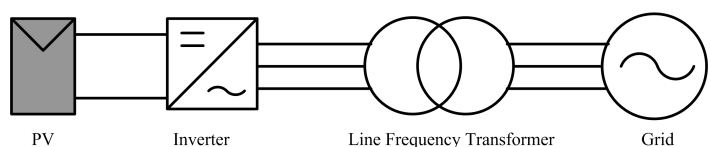

Fig. 8. Structure of single-stage power conversion system for PV system.

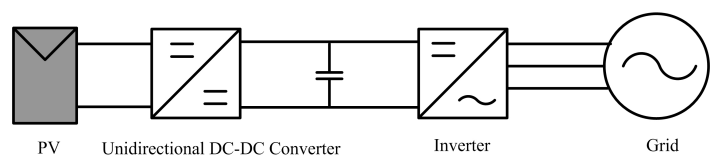

(a)

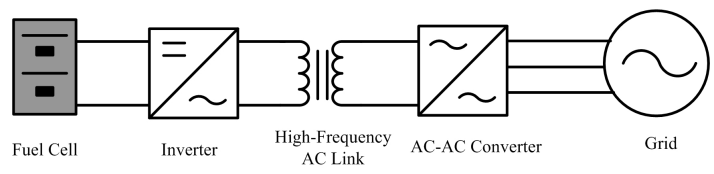

(b)

Fig. 9. Two typical structures of two-stage conversion systems for PV and FC systems. (a) Commonly used two-stage power conversion system for PV system. (b) High-frequency link direct dc-ac power converter for fuel cells.

system for those DER units producing DC voltages [9]. A transformer is usually integrated into the system when the isolation or a high ratio of the voltage conversion is required. It features the simplest structure whereas is compromised by the bulky and expensive line frequency transformer.

Z-source converters [29] and neutral point clamped (NPC) multilevel converters [30] offer alternative approach to avoid the line-frequency transformer. The transformerless converter is still an emerging topology for PV systems, providing the benefits of high efficiency, small size and weight, as well as reduced cost. Nevertheless, additional leakage current is introduced due to the galvanic connection of the grid and the DC source [31]. Appropriate solutions should be considered to minimize the leakage current flowing in the system [32].

2) Two-Stage Power Conversion Systems: The two-stage power conversion system is the most common configuration for all electronically-coupled DER units [33]-[35]. Fig. 9 shows two typical structures of two-stage power conversion system for PV and FC systems, respectively. In general, a two-stage power conversion system consists of a DC-DC converter for those energy sources with DC output voltage, or an AC-DC converter for those energy sources with AC output voltage, together with a grid-connected DC-AC converter. The converter on the energy source side is used to extract the maximum power from the primary energy source, while the grid side converter is controlled to follow grid requirements.

In Fig. 9 (a), instead of the low-frequency transformer in the single-stage power conversion system [9], the DC-DC converter is used for isolation and voltage step-up. Another alternative topology without the low-frequency transformer is the high-frequency AC link converter, as shown in Fig. 9 (b). There are numerous topologies for selecting two-stage power conversion system, as discussed in [7]-[9]. Trends on the renewable energy system are to increase the nominal power (to several megawatts). To reduce the cost and to improve the efficiency of power conversion systems, multilevel converter offers an advantageous option for high power electronicallycoupled DER units. In addition to the NPC and the cascade H-bridge multilevel converters [37], the modular multilevel 


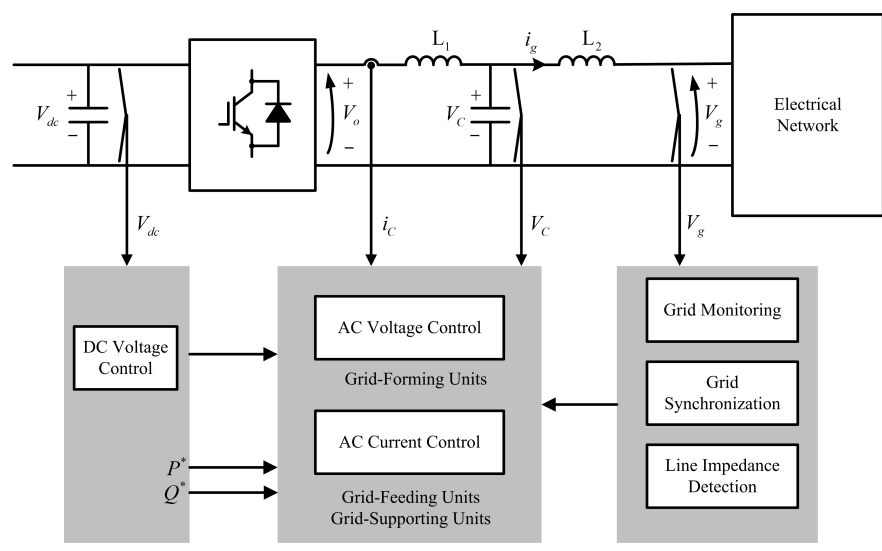

Fig. 10. General control system for an electronically-coupled DER unit within an AC microgrid.

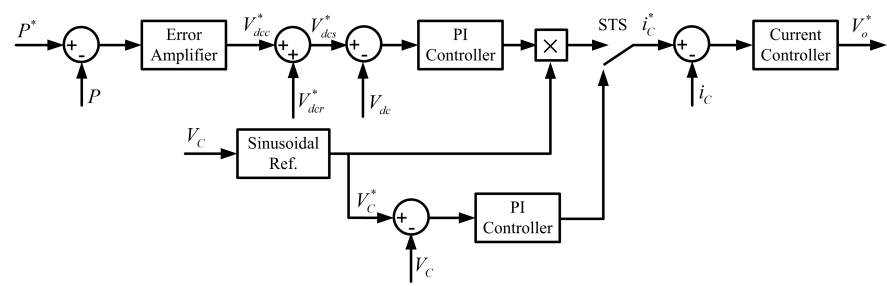

Fig. 11. Block diagram for the ac voltage and current control method using a static transfer switch.

converters are also the promising topologies [38].

\section{Control Methods of Electronically- Coupled DER UNITS}

Generally speaking, control methods for DER units are designed on the basis of possible operating conditions and the desired functions. Fig. 10 illustrates a general control system for an electronically-coupled DER unit in an AC microgrid, where the electronically-coupled DER units can operate as grid-forming units, grid-feeding units, and grid-supporting units.

\section{A. Grid-Forming Units}

Grid-forming units regulate the system voltage and frequency by balancing generation power and load demands when the microgrid operates in islanded operation mode [26]. However, in grid-connected operation mode, as there are voltage and frequency references from the main grid, the gridforming units are changed to operate as current source. Thus, the control methods for grid-forming units should be suitable in both islanded and grid-connected operation modes, so as to ensure smooth transients during microgrid operation mode changes.

In the case where only one DER unit works as the gridforming unit, two types of control methods are available [39][42]. The first one uses a static transfer switch (STS) to allow DER unit operating in two modes: voltage-controlled mode and current-controlled mode, corresponding to the islanded and grid-connected operations, respectively, as shown in Fig. 11 [39]-[41]. The transitions between one and the other mode may bring voltage stability problems during the time delay caused by the islanding detection in the case of non-intentional

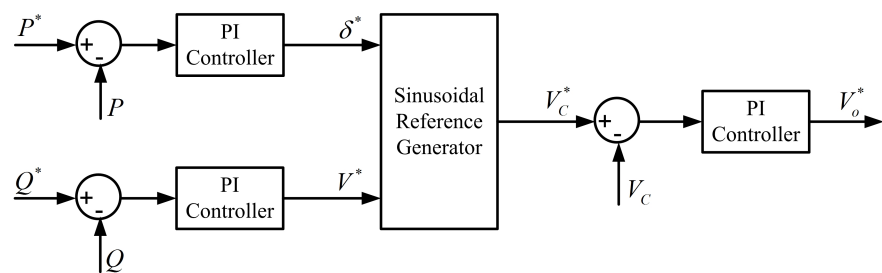

Fig. 12. Block diagram of the basic direct ac voltage control method.

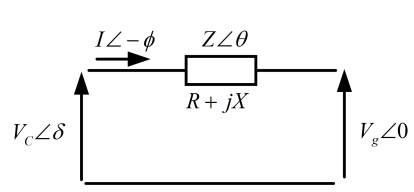

(a) (b)

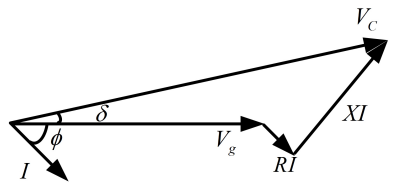

Fig. 13. Simplified diagram of grid-connected DER unit for power flow analysis. (a) Circuit model. (b) Phasor diagrams

islanding situations [42]. Thus, advanced grid monitoring algorithm is required to ensure the STS operate in an automatic manner [41].

The other type is the direct $\mathrm{AC}$ voltage control scheme that controls the amplitude and phase angle of the output AC voltage, as shown in Fig. 12 [42]. This method is based on the principle of power flows between two ac sources.

Fig. 13 depicts the simplified diagram of grid-connected DER unit for power flow analysis. The active and reactive powers produced by the DER unit can be expressed by

$$
\left\{\begin{array}{c}
P=\frac{V_{C}^{2}}{Z} \cos \theta-\frac{V_{C} V_{g}}{Z} \cos (\theta+\delta) \\
Q=\frac{V_{C}^{2}}{Z} \sin \theta-\frac{V_{C} V_{g}}{Z} \sin (\theta+\delta)
\end{array}\right.
$$

where $Z$ is the coupling impedance between the DER unit and microgrid. Normally, this coupling impedance is mainly inductive, due to the output filter and leakage inductance of the transformer. Then the power flows of a DER unit can be simplified in per unit value as

$$
\left\{\begin{array}{l}
P=\frac{V_{C} V_{g}}{X} \sin \delta \\
Q=\frac{V_{C}^{2}-V_{C} V_{g} \cos \delta}{X}
\end{array}\right.
$$

Thus, the desired active and reactive powers can be obtained by controlling the phase angle $\delta$ and the ac voltage $V_{C}$ as follows

$$
\left\{\begin{array}{l}
\delta^{*}=\tan ^{-1}\left(\frac{P^{*} X}{\left(V_{C}^{* 2}-Q^{*} X\right)}\right) \\
V_{C}^{*}=\frac{P^{*} X}{V_{g} \sin \delta^{*}}
\end{array}\right.
$$

The main advantages of a direct AC voltage control method are the compatibility for both microgrid operations without using an extra static switch, and the fast ac voltage response, whereas the quality of injected current into grid is compromised due to the absence of the current regulation loop. In this sense, the control methods based on multiple feedback loops are widely used to integrate both $\mathrm{AC}$ voltage and injected current control options [43].

In the other case where two or more DER units operate as grid-forming units, the load sharing among them complicates 
more the control system. In this sense, droop control methods and active load sharing control techniques are developed, as discussed later.

\section{B. Grid-Feeding Units}

Grid-feeding units adjust the provided active and reactive powers $(P$ and $Q)$ to follow the power dispatch requirements, and to compensate variations in the load and power flow fluctuations in the feeder. There are many control methods proposed for DER units to operate as grid-feeding units. These alternatives can be classified into three categories depending on the use of current controllers, which are current control [44], direct power control (DPC) [49] and ac voltage control [42].

1) Current control methods: Comprehensive overviews of current control methods for grid-connected DER units are provided in [44], [45]. Similar to the Field Oriented Control (FOC) of an induction motor [46], those current control methods can also be distinguished as the Voltage Oriented Control (VOC) and Virtual Flux Oriented Control (VFOC) methods [47]. Instead of synchronizing with the grid voltage, VFOC makes the control system synchronized on the integral of voltage that can be viewed as a filtered grid voltage [48].

Fig. 14 gives a general diagram of VOC control system. The current reference can be generated by either $P$ and $Q$ feed-forward or $P$ and $Q$ feedback loop. Both methods try to mimic the power electronics interfaces as synchronous machines, guarantee high dynamic and static performance via an inner current control loop. Consequently, the control system structure and performance largely depend on the adopted current controllers. In-depth evaluations of current controllers in different reference frames are presented in [45], which involves the Proportional Integral (PI) controllers, Proportional Resonant (PR) controllers, hysteresis controllers, and deadbeat controllers.

2) Direct power control (DPC) methods: The direct power control (DPC) method is developed in analogy to the wellknown direct torque control (DTC) of an induction motor [49]. Instead of torque and stator flux the instantaneous active and reactive power ( $p$ and $q$ ) are controlled. Due to the absence of inner current control loop in the DPC scheme, the coordinate transformation and decoupling between active and reactive power component are not necessary. There are two approaches for power estimation: voltage-based and virtual flux-based. Fig. 15 depicts a diagram of virtual flux-based DPC scheme [50].

Comparative analysis of VOC, VFOC, voltage-based DPC, as well as virtual flux-based DPC methods are provided in [51], [52]. In view of varying switching frequency problem in the DPC method, improved DPC alternatives with constant switching frequency have been developed [53], [54].

Furthermore, to guarantee a stable microgrid with high penetration of DER units, grid-feeding units are normally required to ride through short grid disturbances in the gridconnected operations [55]. On the other hand, in the islanded microgrids, switching of loads can also cause high voltage transients, which consequently require all DER units to support this disturbance [56]. In addition, the appearance of negativesequence component in the system voltage leads to the second harmonic oscillations in the system of DER units. Control methods for DER units under grid fault conditions, in terms of requirements, are categorized as four types in [44]. Different from those control methods for power dispatch, the power calculation algorithms generating current references have a large impact on the system performance. In this sense, several current reference generation algorithms for controlling real power flow are studied in [57].

\section{Grid-Supporting Units}

Grid-supporting units defined here are different from grid parallel units defined in [58]. The grid parallel units are only responsible to feed as much power into the grid as possible.

In contrast, the grid-supporting units are controlled not only to extract maximum active power from their primary energy source, but also to provide ancillary services for the power quality improvement. Recently, a small PV system with the function of power quality conditioner are reported in [59], where a modified Maximum Power Point Tracking (MPPT) algorithm is applied together with a repetitive AC voltage controller for selectively compensating harmonics.

\section{Microgrid Control and Power Management}

Microgrid control and power management involves several issues different than in low voltage distribution networks with DER units. Traditional power systems usually have kinetic energy stored in the generator rotors and these are regarded as essential for the stability of systems [60]. In contrast, power electronics based microgrids are dominated by electronicallycoupled DER units, inherently without inertias, but do offer the possibility of more flexible operation. A further problem is the resistive nature in low-voltage distribution networks, which results in a coupling between active power and system voltage, and consequently complicates the controls of power flows and microgrid voltage profile [64]. Furthermore, the whole energy system in the context of microgrid is expected to be interactive, intelligent and distributed [61]. Advanced supervisory control architectures for the energy management are therefore needed [62].

To ensure that a microgrid operates properly, a three-level hierarchical microgrid control system is proposed in [76]-[78], as shown in Fig. 16. Similar to the hierarchical control for traditional power systems, the hierarchical control system for microgrids is organized as follows. The primary control deals with the instantaneous active and reactive power balances. The secondary control restores system voltage and frequency deviations subsequent to transients and resynchronizes with the main grid. The tertiary control is conceived to perform the long-term energy management tasks. The bandwidth of the control system is gradually decreased from the primary level to tertiary level. The main differences from the hierarchical control for large power systems are in the control methods used at each level.

Here special attentions will be paid to the primary controls of DER units for the instantaneous active and reactive power 


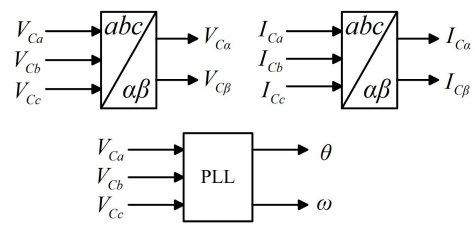

(a)

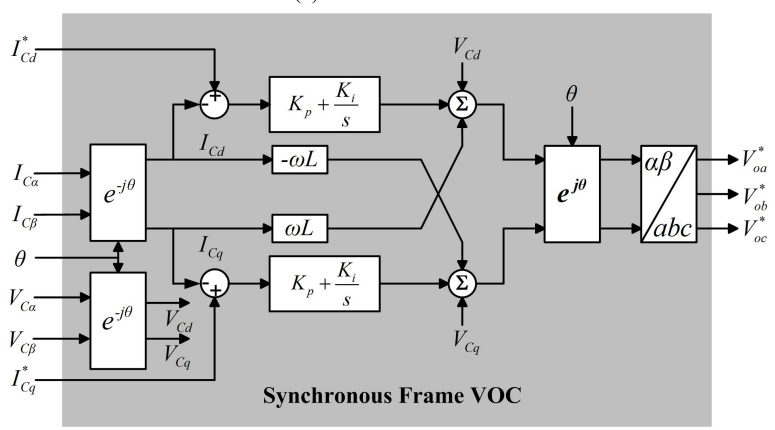

(b)

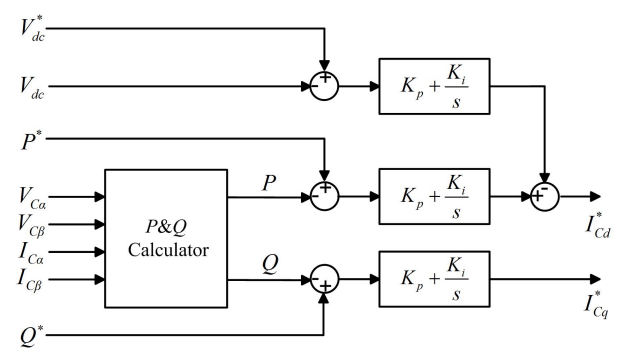

(c)

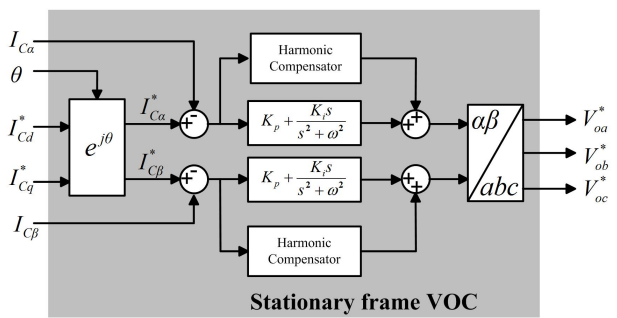

(d)

Fig. 14. Block diagram of the voltage-oriented control method. (a) Phase-locked loop. (b) Current reference generation. (c) Synchronous frame based voltageoriented current controller. (d) Stationary frame voltage-oriented current controller.
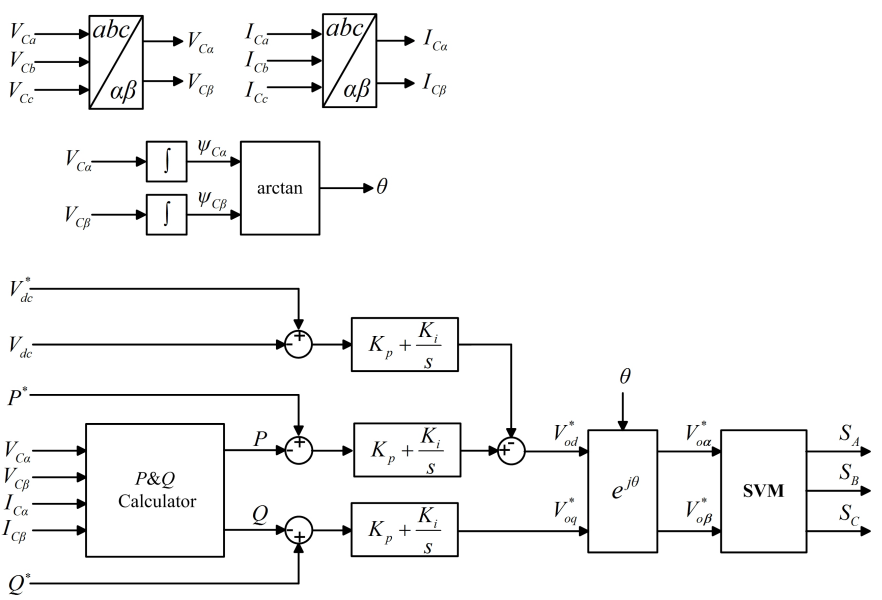

Fig. 15. Block diagram of the virtual flux-based direct power control scheme.

balances, and the supervisory control architectures for longterm energy management.

\section{A. Impact of Load Characteristics}

Load characteristics have a significant impact on microgrid performance such as transient stability and voltage stability. A good understanding of load characteristics is important to perform microgrid control strategies. Load modeling can be done simply by constructing physical models of typical loads such as lamps, heaters, and refrigerators. However, the exact composition of different types of loads is usually difficult to estimate, because of weather, consumer life style and many other factors [64].

A number of load models for system stability analysis have been well summarized in [63]. The load models are generally classified as static models and dynamic models. The effects of dynamic load model like induction motor on the microgrid stability are analyzed in [64]-[66].

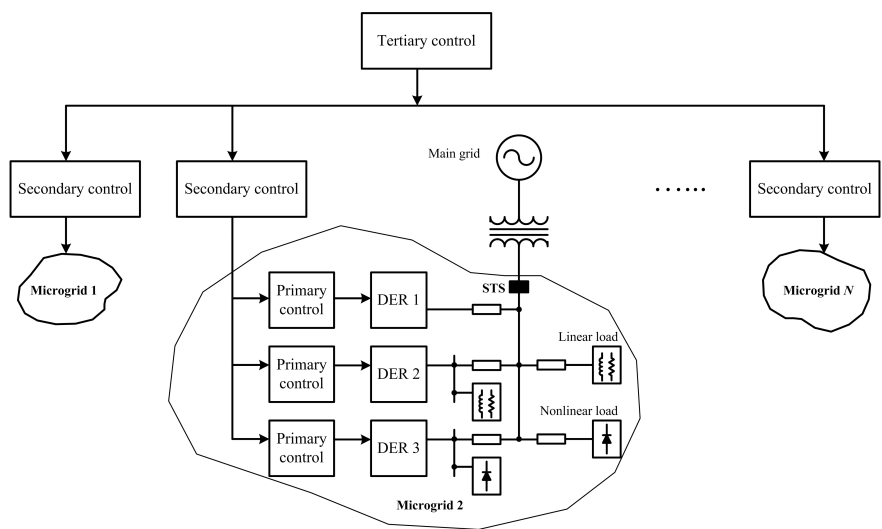

Fig. 16. General architecture of hierarchical microgrid control system.

The static load voltage characteristics can be given by [70],

$$
\left\{\begin{array}{l}
P=P_{N}\left[a_{p}\left(V / V_{N}\right)^{2}+b_{p}\left(V / V_{N}\right)+c_{p}\right] \\
Q=Q_{N}\left[a_{q}\left(V / V_{N}\right)^{2}+b_{q}\left(V / V_{N}\right)+c_{q}\right]
\end{array}\right.
$$

where $V_{N}$ are the nominal voltage, $P_{N}$ and $Q_{N}$ are the active power and reactive power of load at the nominal voltage, $a_{p}$, $b_{p}, c_{p}, a_{q}, b_{q}$, and $c_{q}$ represent the proportion of different types of loads, which should meet the following conditions,

$$
\left\{\begin{array}{l}
a_{p}+b_{p}+c_{p}=1 \\
a_{q}+b_{q}+c_{q}=1
\end{array}\right.
$$

Similarly, the frequency dependency of load characteristics also can be expressed by using polynomials as follows,

$$
\left\{\begin{array}{l}
P=P_{N}\left[a_{p}\left(V / V_{N}\right)^{2}+b_{p}\left(V / V_{N}\right)+c_{p}\right]\left(1+K_{p f} \Delta f\right) \\
Q=Q_{N}\left[a_{q}\left(V / V_{N}\right)^{2}+b_{q}\left(V / V_{N}\right)+c_{q}\right]\left(1+K_{q f} \Delta f\right)
\end{array}\right.
$$

where $\Delta f$ is the frequency deviation from the nominal frequency $f_{0}$. Based on (4) and (6), the effects of static load voltage and frequency characteristics on the performance of primary droop control system are discussed in [67]-[69]. It is shown that the voltage and frequency dependencies of loads require DER units to adopt the active power-frequency $(P-\omega)$ 
and reactive power-voltage $(Q-V)$ droop characteristics rather than the opposite droop relationships in microgrids.

\section{B. Instantaneous Power Balancing Strategies}

Instantaneous active and reactive power balances in microgrids are generally guaranteed by the instantaneous load following and load sharing among DER units. Since the focus here is on the primary control strategies for DER units, the load shedding algorithms for instantaneous load following will not be involved. Controls of DER units for instantaneous load sharing will be discussed.

As pointed out previously, the characteristics of loads and DER units determine the frequency and voltage stability in microgrids. Hence, although a number of control schemes have been proposed for parallel operation of uninterruptible power supply (UPS) inverters [71], their applicability for load sharing in microgrids should be further studied. With respect to the use of critical communication links, two groups of strategies are available for instantaneous load sharing in microgrids, includes active load (current or power) sharing and the droop control methods.

1) Active Load (Current or Power) Sharing Methods: Active load (current or power) sharing methods involve the master-slave approach [72] and the current limitation control [73]. In this kind of control strategies, the DER unit operating as grid-forming (master) unit regulates the system voltage and frequency, whereas the rest of DER (slave) units receive the current references, through communication links, from either the master unit or the previous slave unit. Any DER unit in the microgrid can be the master.

The use of critical communication links may perform well for the parallel operation of inverters in the same equipment cabinet, but imposes several challenges for load sharing in microgrids. The most obvious drawback is that the limited bandwidth of signal communication leads the master unit to take up most of nonlinear loads in the microgrid. Hence, the distorted powers are often compensated locally by DER unit itself without using communication links in the improved active load sharing method [56].

2) Droop Control Methods: Droop control methods are based on the well-known correlation between frequency and active power flows in traditional power systems. In analogy to ac generators, the frequency of DER unit decreases when extra loads comp up and increases when there is an excess of active power in microgrids, consequently the virtual inertias of electronically-coupled DER units are emulated. Instead of using critical communication links, droop control methods allow DER units to automatically share the total load by measuring the locally available variables (output voltage and current), thus furnishing higher reliability and flexibility [74].

Normally, droop control methods can be further split into two types, i.e. the mater-slave and multi-master droop control. Master-slave droop control is a composite use of master-slave control and droop control. It is appropriate for the case that single or several DER unit acts as the grid-forming (master) units and the rest of units operate as the grid-feeding (slave) units [75]. On the other hand, in the multi-master droop

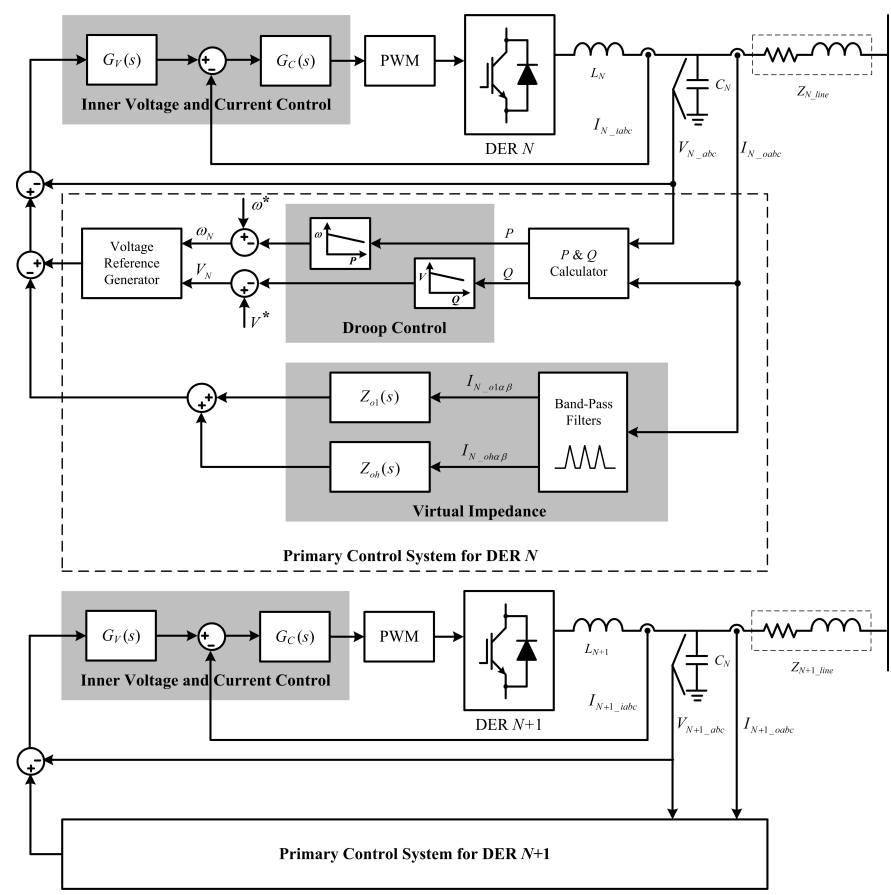

Fig. 17. Block diagram of the virtual impedance based droop control method.

control, there is no distinguish between grid-forming units and grid-feeding units. In fact, all DER units operate as gridforming units [79].

However, it is known that there are several limitations on using conventional $P-\omega$ and $Q-V$ droop control method in microgrids, due to the characteristics of distribution lines and loads. For the static performance of microgrids, the low X/R ratio of distribution line impedance affects the load sharing accuracy. Furthermore, harmonic and unbalanced powers are poorly compensated in the appearance of nonlinear and unbalanced loads. For the dynamic behavior of microgrids, the voltage and frequency dependencies of loads have to be taken into account when choosing droop characteristics for DER units, otherwise controllers may fail to ensure a proper sharing and lead to instability.

To mitigate abovementioned drawbacks, several improved variations based on the $P-\omega$ and $Q-V$ droop characteristics are available [79]-[86]. The first method presents novel droop characteristics between different frequency components of the controlled signal (ac voltage) and the active power $(P)$, reactive power $(Q)$ and distortion power $(D)$, respectively. Thus, the use of $Q-V$ droop characteristic is avoided, and the line impedance effect are eliminated. Moreover, the distorted powers which result from nonlinear and unbalanced loads are compensated by using the $D-\omega_{d}$ droop characteristic, where $\omega_{d}$ is the drooping frequency component caused by the distortion power. However, the injection of high-frequency signals limits the power rating of DER units and the increased voltage distortions at the outputs of DER units.

The second group of methods is based on the virtual output impedance concept [81]-[84]. These alternatives adopt the multiple feedback loop control, where the virtual impedance is emulated by using a load current feedforward loop. Fig. 17 illustrates the block diagram of the virtual impedance based droop control method. 
It is known that the well-designed output impedances of DER units are essential for accurate load sharing. Various output impedances can be obtained by applying different droop algorithms [81]. However, because of the limitations of load characteristics, the droop algorithms cannot be selected arbitrarily. Thus, the virtual impedance is usually designed larger than the closed-loop output impedance, so as to offer the possibility of controlling output impedance of a DER unit. In contrast to physical impedance, the virtual impedance has no power losses. Furthermore, the virtual impedance can provide additional benefit for the plug-and-play operations of DER units [82].

Different from the series impedance of a synchronous generator which is mainly inductive, the output impedances of electronically-coupled DER units can be chosen arbitrarily, which consequently provides a flexible way to deal with the effects of line impedance and load characteristics. In [83], the output impedance consists of inductance and resistance connected in parallel is proposed for accurately sharing nonlinear loads. It is designed independently to present inductive behavior around the fundamental frequency and resistive behavior for low-order harmonic currents. The main drawback of this method is the increased harmonic voltage distortion at the terminal of DER units.

Recently, the resistive active filtering scheme is applied in electronically-coupled DER units for active compensation of distorted powers [85], [86]. A droop relationship between the total harmonic VAR and harmonic conductance is developed to share nonlinear loads [84], as shown in Fig. 18. Compared with the virtual impedance scheme, this method effectively damps harmonic voltage distortions at the output of DER units. Moreover, only a high bandwidth current control loop is needed, which consequently simplifies the inner voltage and current control loop design. However, the performance of this method is deteriorated because of the mismatch between the harmonic inductance and characteristic impedance of distribution line [87].

\section{Supervisory Control for Energy Management}

There are two types of supervisory control architecture (i.e. centralized or decentralized) for performing microgrid energy management system. In the centralized control architecture, a microgrid central controller, on the basis of DER and load bids, security constraints and other factors, sends the control setpoints to the local controllers of gird-forming units and controllable load through the two-way communication links [88]. The disadvantage of the centralized control is low reliability and redundancy. Also it requires the knowledge of all DER units and loads within it, and consequently reducing its scalability.

On the other hand, the decentralized control architecture based on the multi-agent system (MAS) technology is presented [89]. In this architecture each DER unit has a certain level of autonomy on the coordinate control of a microgrid. Besides the power balancing control task, economic functions and power optimization algorithms are also imposed on the local controller of the DER units and controllable

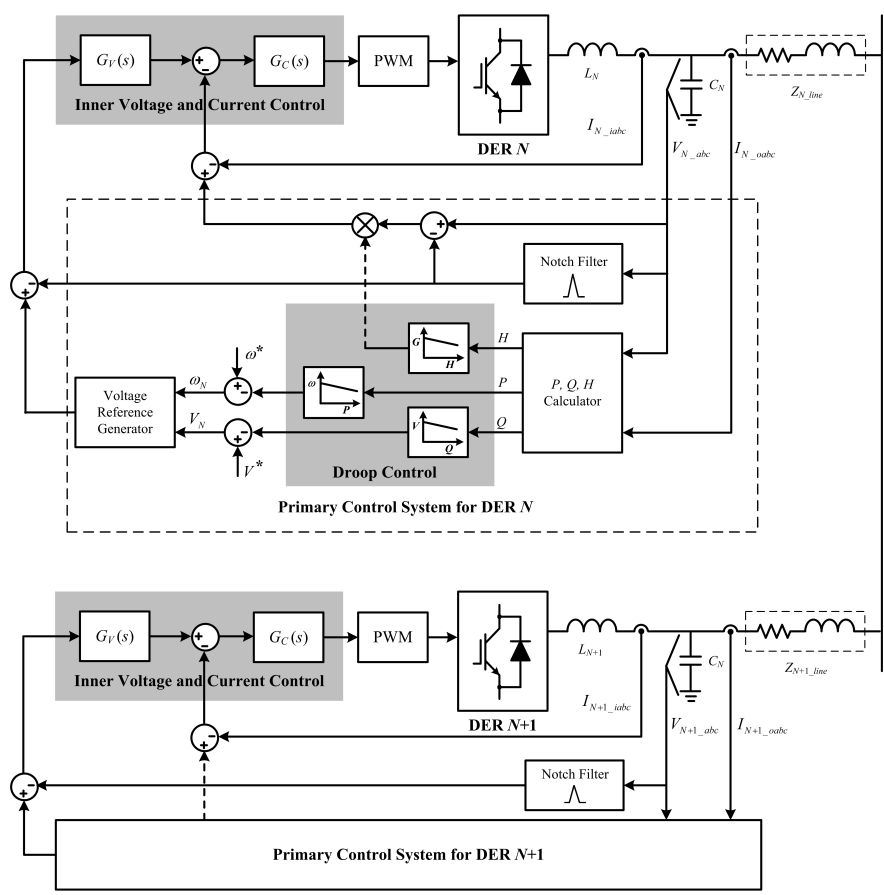

Fig. 18. Block diagram of the resistive active filtering based droop control method.

load. Those intelligent agents are a piece of software with autonomy, proactively, and social ability to co-operate with other agents by means of some communication language. The agent platform is a software environment in which software agents run. It consists of the machines, operating system, agent management system and the agents.

Communication system plays an essential role in both two types of supervisory control system. Supervisor Control and Data Acquisition (SCADA) software is usually adopted in the centralized control architecture. Java-Jade provides another software platform for multi-agent system in a decentralized control system [90].

\section{Future TREndS AND CONCLUSIONS}

This paper has given an overview of power electronics based microgrids, in terms of microgrid configurations, structures and control methods for electronically-coupled DER units, as well as microgrid power and energy management strategies. For the microgrid configurations, dc microgrids and highfrequency ac microgrids have been shown superior performances on some special applications such as low voltage and geographically small networks. Hence, by comprising low voltage dc buses and ac buses with different frequencies according to the load requirements, hybrid dc- and ac-coupled microgrids will present advantageous performance for integrating DER units.

The options in structures of DER units and appropriate choosing power electronics topologies have been discussed. Transformerless dc-ac converter is an emerging topology for PV systems. As the increasing nominal power of DER units, multilevel converters provide effective ways to reduce the cost and improve the efficiency. Control methods for electronicallycoupled DER units at different operating conditions were described. Multiloop control approach with both ac voltage 
and current loops is a promising method for grid-forming operations of DER units.

The significance of load characteristics for microgrids operation and control are also clear. Under the effects of load and line impedance characteristics, various load sharing strategies among DER units were compared for instantaneous active and reactive power managements. Two robust methods have been shown effective to against adverse influences. One type is the combined use of low-bandwidth communication links for average power sharing and local controls for nonlinear and unbalanced loads. The other one is the droop control method based on the virtual output impedance.

Finally, the multilevel hierarchical control architecture for microgrid power and energy managements has been described. Control architectures based on the centralized and distributed technologies were compared, and pointed out that modern microgrid has to become intelligent and flexible by the help of telecommunication infrastructures and the next generation of information technologies.

\section{REFERENCES}

[1] J. M. Guerrero, F. Blaabjerg, T. Zhelev, K. Hemmes, E. Monmasson, S. Jemei, M. P. Comech, R. Granadino, and J. I. Frau, "Distributed generation: Toward a new energy paradigm," IEEE Ind. Electron. Mag., Vol. 4, No. 1, pp. 52-64, Mar. 2010.

[2] European Commission-New ERA for electricity in Europe. Distributed Generation: Key Issues, Challenges and Proposed Solutions, EUR 20901, ISBN 92-894-6262-0, 2003.

[3] R. Lasseter, "Smart distribution: Coupled microgrids," IEEE Proc., Vol. 99, No. 6, pp. 1074-1082, Jun. 2011

[4] M. Barnes, J. Kondoh, H.Asano, J. Oyarzabal, G. Venkataramanan, R. Lasseter, N. Hatziargyriou, and T. Green, " Real-world microgrids - an overview," in Proc. IEEE SoSE, pp. 1-8, 2007.

[5] N. Hatziargyriou, H. Asano, R. Iravani, and C. Marnay, "Microgrids,"IEEE Power Energy Mag., Vol. 6, No. 4, pp. 78-94, Jul./Aug. 2007.

[6] Q. Zhang, R. Callanan, M. K. Das, S. H. Ryu, A. K. Agarwal, and J. W. Palmour, "SiC power devices for microgrids," IEEE Trans. Power Electron., Vol. 25, No. 12, pp. 2889-2896, Dec. 2010.

[7] Z. Chen, J. M. Guerrero, and F. Blaabjerg, "A review of the state of the art of power electronics for wind turbines," IEEE Trans. Power Electron., Vol. 24, No. 8, pp. 1859-1875, Aug. 2009.

[8] F. Blaabjerg, Z. Chen, and S. B. Kjaer, "Power electronics as efficient interface in dispersed power generation systems," IEEE Trans. Power Electron., Vol. 19, pp. 1184-1194, Sep. 2004.

[9] S. B. Kjaer, J. Pedersen, and F. Blaabjerg, "A review of single-phase grid-connected inverters for photovoltaic modules," IEEE Trans. Ind. Appl., Vol. 41, No. 5, pp. 1292-1306, Sep./Oct. 2005.

[10] S. Chakraborty and M. G. Simoes, "Advanced active filtering in a single high frequency AC microgrid," in Proc. IEEE PESC, pp. 191-197, 2005.

[11] S. Chakraborty, M. D. Weiss, and M. G. Simoes, "Distributed intelligent energy management system for a single-phase high-frequency ac microgrid," IEEE Trans. Ind. Electron., Vol. 54, No. 1, pp. 1-13, Feb. 2007.

[12] J. Driesen and F. Katiraei, "Design for distributed energy resources,"IEEE Power and Energy Mag., Vol. 6, No. 3, pp. 30-40, May/Jun. 2008.

[13] H. Kakigano, Y. Miura, and T. Ise, "Low-voltage bipolar-type DC microgrid for super high quality distribution," IEEE Trans. Power Electron., Vol. 25, No. 12, pp. 3066-3075, Dec. 2010.

[14] K. Mizuguchi, S. Muroyama, Y. Kuwata, and Y. Ohashi, "A new decentralized dc power system for telecommunications systems," in Proc. IEEE INTELEC, pp. 55-62, 1990.

[15] C. C. Chan, "The state of art of electric and hybrid vehicles," Proc. IEEE, Vol. 90, No. 2, pp. 247-275, Feb. 2002

[16] J. Ciezki and R. Ashton, "Selection and stability issues associated with a navy shipboard dc zonal electric distribution system," IEEE Trans. Power Del., Vol. 15, No. 2, pp. 665-669, Apr. 2000.
[17] D. Salomonsson and A. Sannino, "Low-voltage dc distribution system for commercial power systems with sensitive electronic loads," IEEE Trans. Power Del., Vol. 22, No. 3, pp. 1620-1627, Jul. 2007.

[18] A. Kwasinski and C. N. Onwuchekwa, "Dynamic behavior and stabilization of DC microgrids with instantaneous constant-power loads," IEEE Trans. Power Electron., Vol. 26, No. 3, pp. 822-834, Mar. 2011.

[19] D. Salomonsson, L. Soder and A. Sannino, "Protection of low-voltage DC microgrids," IEEE Trans. Power Del., Vol. 24, No. 3, pp. 1045-1053, Jul., 2009.

[20] A. Sannino, G. Postiglione, and M. Bollen, "Feasibility of a dc network for commercial facilities," IEEE Trans. Ind. Appl., Vol. 39, No. 5, pp. 1499-1507, Sep./Oct., 2003.

[21] U. Borup, B. Nielsen, and F. Blaabjerg, "Compensation of cable voltage drop and automatic identification of cable parameters in $400 \mathrm{~Hz}$ ground power units," IEEE Trans. Ind. Appl., Vol. 40, No. 5, pp. 1281-1286, Sep./Oct., 2004.

[22] I. Takahashi and G. Su, "A $500 \mathrm{~Hz}$ power system-applications," in Proc. IEEE IAS, pp. 996-1002, 1989.

[23] Z. Jiang and X. Yu, "Hybrid DC- and AC-linked microgrids: towards integration of distributed energy resources," in Proc. IEEE Energy 2030, pp. 1-8, 2007.

[24] S. Barave and B. Chowdhury, "Hybrid AC/DC power distribution solution for future space applications," in Proc. IEEE PESGM, pp. 1-8, 2007.

[25] K. Hirose, T. Takeda, and A. Fukui, "Field demonstration on multiple power quality supply system in Sendai, Japan," in Proc. EPQU, pp. 1-6, 2007.

[26] F. Katiraei, R. Iravani, N. Hatziargyriou, and A. Dimeas, "Microgrids management," IEEE Power and Energy Mag., Vol. 6, No. 3, pp. 54 -65, May/Jun. 2008.

[27] R. Lasseter, J. Eto, B. Schenkman, J. Stevens, H. Vollkommer, D. Klapp, E. Linton, H. Hurtado, and J. Roy, "CERTS microgrid laboratory test bed," IEEE Trans. Power Del., Vol. 26, No. 1, pp. 325-332, Jan. 2011.

[28] H. Nikkhajoei and R. Lasseter, "Distributed generation interface to the CERTS microgrid," IEEE Trans. Power Del., Vol. 24, No. 3, pp. 15981608, Jul. 2009.

[29] F. Peng, "Z source inverter," IEEE Trans. Ind. Appl., Vol. 39, No. 2, pp. 504-510, Mar./Apr. 2003.

[30] R. Gonzalez, E. Gubia, J. Lopez, and L. Marroyo, "Transformerless single-phase multilevel-based photovoltaic inverter," IEEE Trans. Ind. Electron., Vol. 55, No. 7, pp. 2694-2702, Jul. 2008.

[31] O. Lopez, R. Teodorescu, F. Freijedo, and J. Dovalgandoy, "Leakage current evaluation of a single phase transformerless PV inverter connected to the grid," in Proc. IEEE APEC, pp. 907-912, 2007.

[32] M. Cavalcanti, K. de Oliveira, A. de Farias, F. Neves, G. Azevedo, and F. Camboim, "Modulation technique to eliminate leakage currents in transformerless three-phase photovoltaic systems," IEEE Trans. Ind. Electron., Vol. 57, No. 4, pp. 1360-1368, Apr. 2010.

[33] Y. Song, S. Chung, and P. Enjeti, "A current-fed link direct DC/AC converter with active harmonic filter for fuel cell power systems," in Proc. IEEE IAS, pp.123-128, 2004.

[34] S. Ponnaluri, G. Linhofer, J. Steinke, and P. Steimer, "Comparison of single and two stage topologies for interface of BESS or fuel cell system using the ABB standard power electronics building blocks," in Proc. EPE, pp. 1-9, 2005.

[35] S. Inoue and H. Akagi, "A bidirectional isolated DC-DC converter as a core circuit of the next-generation medium-voltage power conversion system," IEEE Trans. Power Electron., Vol. 22, No. 2, pp. 535-542, Mar. 2007.

[36] S. Alepuz, S. Monge, J. Bordonau, J. Gago, D. Gonzalez, and J. Balcells, "Interfacing renewable energy sources to the utility grid using a threelevel inverter," IEEE Trans. Ind. Electron., Vol. 53, No. 5, pp. 1504-1511, Oct. 2006.

[37] L. Maharjan, S. Inoue, H. Akagi, and J. Asakura, "State-of-charge (SOC) balancing control of a battery energy storage system based on a cascade PWM converter," IEEE Trans. Power Electron., Vol. 24, No. 6, pp. 16281636, Jun. 2009.

[38] A. Watson, H. Dang, G. Mondal, J. Clare, and P. Wheeler, "Experimental implementation of a multilevel converter for power system integration," in Proc. IEEE ECCE, pp. 2232-2238, 2009.

[39] R. Tirumala, N. Mohan, and C. Henze, "Seamless transfer of gridconnected PWM inverters between utility- interactive and stand-alone modes," in Proc. IEEE APEC, pp.1081-1086, 2002.

[40] F. Pai, "An improved utility interface for microturbine generation system with stand-alone operation capabilities," IEEE Trans. Ind. Appl., Vol. 53, No. 5, pp. 1529-1537, Oct. 2006. 
[41] R. Teodorescu and F. Blaabjerg, "Flexible control of small wind turbines with grid failure detection operating in stand-alone and grid-connected mode," IEEE Trans. Power Electron., Vol. 19, No. 5, pp. 1323-1332, Sep., 2004.

[42] H. Kim, T. Yu, and S. Choi, "Indirect current control algorithm for utility interactive inverters in distributed generation systems," IEEE Trans. Power Electron., Vol. 23, No. 3, pp.1342-1347, May 2008.

[43] J. Kim, J. M. Guerrero, P. Rodriguez, and R. Teodorescu, and K. Nam, "Mode adaptive droop control with virtual output impedances for an inverter-based flexible AC microgrid," IEEE Trans. Power Electron., Vol. 26, No. 3, pp. 689-701, Mar. 2011.

[44] F. Blaabjerg, R. Teodorescu, M. Liserre, and A. Timbus, "Overview of control and grid synchronization for distributed power generation system," IEEE Trans. Ind. Electron., Vol. 53, No. 5, pp. 1398-1409, Oct. 2006

[45] A. Timbus, M. Liserre, R. Teodorescu, P. Rodriguez, and F. Blaabjerg, "Evaluation of current controllers for distributed power generation systems," IEEE Trans. Power Electron., Vol. 24, No. 3, pp. 654-664, Mar. 2009.

[46] D. Novotny and T. Lipo, Vector Control and Dynamics of AC Drives. Oxford University Press, 1996.

[47] M. Kazmierkowski, R. Krishnan, and F. Blaabjerg, Control in Power Electronics. London, U.K.: Academic, 2002.

[48] S. Bhattacharya, A. Vetman, D. Divan, and R. Lorenz, "Flux-based active filter controller," IEEE Trans. Ind. Appl., Vol. 32, No. 3, pp. 491-502, May/Jun. 1996.

[49] T. Noguchi, H. Tomiki, S. Kondo, and I. Takahashi, " Direct power control of PWM converter without power-source voltage sensors," IEEE Trans. Ind. Appl., Vol. 34, No. 3, pp. 473-479, May/Jun. 1998.

[50] M. Malinowski, M. Kazmierkowski, S. Hansen, F. Blaabjerg, and G. Marques, "Virtual flux based direct power control of three-phase PWM rectifiers," IEEE Trans. Ind. Appl., Vol. 37, No. 4, pp. 1019-1027, Jul./Aug. 1998.

[51] M. Malinowski, M. Kazmierkowski, and A. Trzynadlowski, "A comparative study of control techniques for PWM rectifier in AC adjustable speed drives," IEEE Trans. Power Electron., Vol. 18, No. 6, pp. 13901396, Nov. 2003.

[52] J. Alonso-Martinez, J. E. Carrasco, and S. Arnaltes, "Table-based direct power control: a critical review for microgrid applications," IEEE Trans. Power Electron., Vol. 25, Vo. 12, pp. 2949-2961, Dec. 2010

[53] D. Zhi, L. XU, and B. Williams, "Improved direct power control of grid-connected DC/AC converters," IEEE Trans. Power Electron., Vol. 24, No. 5, pp. 1280-1292, May 2009.

[54] S. Aurtenechea, M. Rodriguez, E. Oyarbide, and J. Torrealday, "Predictive control strategy for DC/AC converters based on direct power control," IEEE Trans. Ind. Electron., Vol. 54, No. 3, pp. 1267-1271, Jun. 2007.

[55] G. Saccomando, J. Svensson, and A. Sannimo, "Improving voltage disturbance rejection for variable-speed wind turbines," IEEE Trans. Energy Conv., Vol. 17, No. 3, pp. 422-428, Sep. 2002.

[56] M. Prodanovic and T. Green, "High-quality power generation through distributed control of a power park microgrid," IEEE Trans. Ind. Electron., Vol. 53, No. 5, pp. 1471-1482, Oct. 2006.

[57] P. Rodriguez, A. Timbus, R. Teodorescu, M. Liserre, and F. Blaabjerg, "Flexible active power control of distributed power generation systems during grid faults," IEEE Trans. Ind. Electron., Vol. 54, No. 5, pp. 25832592, Oct. 2007.

[58] P. Strauss and A. Engler, "AC coupled PV hybrid systems and microgrids-state of the art and future trends," in Proc. World Conf. on Photovoltaic Energy Conversion, pp. 2129-2134, 2001.

[59] J. Vasquez, R. Mastromauro, J. M. Guerrero, and M. Liserre, "Voltage support provided by a droop-controlled multifunctional inverter," IEEE Trans. Ind. Electron., Vol. 56, No. 11, pp. 4510-4519, Nov. 2009.

[60] A. Bergen, Power Systems Analysis. Englewood Cliffs, NJ: PrenticeHall, 1986.

[61] C. Hernandez-Aramburo, T. Green, and N. Mugniot, "Fuel consumption minimization of a microgrid," IEEE Trans. Ind. Appl., Vol. 41, No. 3, pp. 673-681, May/Jun. 2005

[62] M. Simoes, "Intelligent based hierarchical control power electronics for distributed generation systems," in Proc. IEEE PESGM, pp. 1-7, 2006.

[63] IEEE Task Force on Load Representation for Dynamic Performance, "Load representation for dynamic performance analysis," IEEE Trans. Power Syst., Vol. 8, No. 2, pp. 472-482, May 1993.

[64] N. Pogaku, M. Prodanovic, and T. Green, "Modeling, analysis and testing of an inverter-based microgrid," IEEE Trans. Power Electron., Vol. 22, No. 2, pp. 613-625, Mar. 2007.
[65] F. Katiraei, M. Iravani, and P. Lehn, "Small-signal dynamic model of a micro-grid including conventional and electronically interfaced distributed resources," IET Gen., Transm., Distrib., Vol. 1, No. 3, pp. 369-378, May 2007.

[66] G. Diaz, C. Gonzalez-Moran, J. Gomez-Aleixandre, and A. Diez, "Composite loads in stand-alone inverter based microgrids-modeling procedure and effects on load margin," IEEE Trans. Power Syst., Vol. 25, No. 2, pp. 894-905, May 2010.

[67] Z. Chen and Y. Hu, "Control of power electronic converters for distributed generation units" in Proc. IEEE IECON, pp. 1317-1322, 2005.

[68] Y. Mohamed and E. El-Saadany, "Adaptive decentralized droop controller to preserve power sharing stability of parallel inverters in distributed generation microgrids," IEEE Trans. Power Electron., Vol. 23, No. 6, pp. 2806-2816, Nov. 2008.

[69] H. Zeinelidin and J. Kirtley, "Micro-grid operation of inverter based distributed generation with voltage and frequency dependent loads," in Proc. IEEE PESGM, pp. 1-6, 2009.

[70] P. Kundur, Power system stability and control. New York: McGraw-Hill, 1994.

[71] J. M. Guerrero, L. Huang, and J. Uceda, "Control of distributed uninterruptible power supply systems," IEEE Trans. Ind. Electron., Vol. 55, No. 8, pp. 2845-2859, Aug. 2008.

[72] T. Green and M. Prodanovic, "Control of inverter-based micro-grids," Electric Power Systems Research, Vol. 77, No. 9, pp. 1204-1213, Jul. 2007.

[73] S. Chiang, C. Lin, and C. Yen, "Current limitation control technique for parallel operation of UPS inverters," in Proc. IEEE PESC, pp. 19221926, 2004.

[74] M. Chandokar, D. Divan, and R. Adapa, "Control of parallel connected inverters in standalone ac supply systems," IEEE Trans. Ind. Appl., Vol. 29, No. 1, pp. 136-143, Jan. 1993.

[75] J. Lopes, C. Moreira and A. Madureira, "Defining control strategies for microgrids islanded operation," IEEE Trans. Power Syst., Vol. 21, No. 2, pp. 916-924, May 2006.

[76] N. Gil and J. Lopes, "Hierarchical frequency control scheme for islanded multi-microgrids operation," in Proc. IEEE Power Tech, pp. 473-478, 2007.

[77] J. M. Guerrero, J. C. Vasquez, J. Matas, M. Castilla, and L. G. Vicuna, "Control strategy for flexible microgrid based on parallel line-interactive UPS systems," IEEE Trans. Ind. Electron., Vol. 56, No. 3, pp. 726-736, Mar. 2009.

[78] J. M. Guerrero, J. C. Vasquez, J. Matas, L. G. Vicuna, and M. Castilla, "Hierarchical control of droop-controlled AC and DC microgrids- a general approach toward standardization," IEEE Trans. Ind. Electron., Vol. 58, No. 1, pp. 158-172, Jan. 2011.

[79] A. Tuladhar, H. Jin, T. Unger, and K. Mauch, "Control of parallel inverters in distributed ac power systems with consideration of line impedance," IEEE Trans. Ind. Appl., Vol. 36, No. 1, pp. 131-138, Jan./Feb. 2000.

[80] M. Marwali, J. Jung, and A. Keyhani, "Control of distributed generation systems-Part II: Load sharing control,” IEEE Trans. Power Electron., Vol. 19, No. 6, pp.1551-1561, Nov. 2004.

[81] J. Matas, M. Castilla, L. G. Vicuna, J. Miret, and J. Vasquez, "Virtual impedance loop for droop-controlled single-phase parallel inverters using a second-order general-integrator scheme," IEEE Trans. Power Electron., Vol. 25, No. 12, pp. 2993-3002, Dec. 2010.

[82] J. M. Guerrero, J. Matas, L. G. Vicuna, M. Castilla, and J. Miret, "Wireless-control strategy for parallel operation of distributed-generation inverters," IEEE Trans. Ind. Electron., Vol. 53, No. 5, pp. 1461-1470, Oct. 2006.

[83] J. M. Guerrero, L. G. Vicuna, J. Matas, M. Castilla, and J. Miret, "A wireless-controller to enhance dynamic performance of parallel inverters in distributed generation systems," IEEE Trans. Power Electron., Vol. 19, No. 5, pp. 1205-1213, Sep. 2006.

[84] D. De and V. Ramanarayanan, "Decentralized parallel operation of inverters sharing unbalanced and non-linear loads," IEEE Trans. Power Electron., Vol. 25, No. 12, pp. 1126-1132, Dec. 2010.

[85] T. Lee, and P. Cheng, "Design of a new cooperative harmonic filtering strategy for distributed generation interface converters in an islanding network," IEEE Trans. Power Electron., Vol. 22, No. 5, pp. 1919-1927, Sep. 2007.

[86] P. Cheng, C. Chen, T. Lee, and S. Kuo, "A cooperative imbalance compensation method for distributed-generation interface converters," IEEE Trans. Ind. Appl., Vol. 45, No. 2, pp. 805-815, Mar./Apr. 2009. 
[87] K. Wada, H. Fujita, and H. Akagi, "Considerations of a shunt active filter based on voltage detection for installation on a long distribution feeder," IEEE Trans. Ind. Applicat., Vol. 38, pp. 1123-1130, Jul./Aug. 2002.

[88] A. Tsikalakis and N. Hatziargyriou, "Centralized control for optimizing microgrids operation," IEEE Trans. Energy Conv., Vol. 23, No. 1, pp. 241-248, Mar. 2008.

[89] L. Dimeas and N. Hatziargyriou, "Operation of a multi-agent system for microgrid control," IEEE Trans. Power Syst., Vol. 20, No. 3, pp. 1447-1455, Aug., 2005.

[90] N. Hatziargyriou, A. Dimeas, S. Hatzivasiliadis, J. Jimeno, and J. Oyarzabal, "DB3: Decentralized control concepts," EU More Microgrid, Work Package B, Feb. 2008.

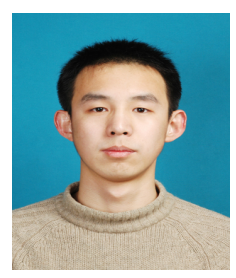

Xiongfei Wang was born in Shijiazhuang, China in 1984. He received the B.S. degree in electrical engineering from Yanshan University, Qinhuangdao, China in 2006, and the M.S. degree in electrical engineering from Harbin Institute of Technology, Harbin, China in 2008. He was a visiting student in Hanyang University, Korea between 2007 and 2008. Since 2009, he has been with Department of Energy Technology, Aalborg University, Denmark, where he is currently pursuing the $\mathrm{PhD}$ degree. His research interests are in the areas of grid integration of renewable energy systems, distributed generations, and microgrids.

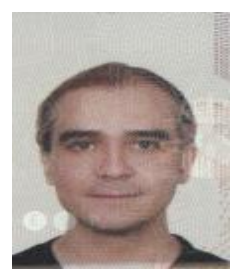

Josep M. Guerrero (S'01-M'04-SM'08) was born in Barcelona, Spain, in 1973. He received the B.S. degree in telecommunications engineering, the M.S. degree in electronics engineering, and the Ph.D. degree in power electronics from the Technical University of Catalonia, Barcelona, Spain, in 1997, 2000 and 2003, respectively. He was an Associate Professor with the Department of Automatic Control Systems and Computer Engineering, Technical University of Catalonia, Barcelona, where was teaching courses on digital signal processing, FPGAs, microprocessors, and renewable energy. Since 2004, he has been responsible for the Renewable Energy Laboratory, Escola Industrial de Barcelona. He has been a visiting Professor at Zhejiang University, China, and University of Cergy-Pontoise, France. From 2011 he is a Full Professor at the Department of Energy Technology, Aalborg University, Denmark, where he is the responsible of the Microgrids research program. His research interests are oriented to different Microgrids aspects, including power electronics, distributed energy storage systems, hierarchical and cooperative control and energy management systems and optimization of microgrids and islanded minigrids. Dr. Guerrero is an Associate Editor for the IEEE TRANSACTIONS ON POWER ELECTRONICS, IEEE TRANSACTIONS ON INDUSTRIAL ELECTRONICS, and IEEE INDUSTRIAL ELECTRONICS MAGAZINE. He has been Guest Editor of the IEEE Transactions on Power Electronics Special Issues: Power Electrics for Wind Energy Conversion and Power Electronics for Microgrids; and the IEEE Transactions on Industrial Electronics Special Sections: Uninterruptible Power Supplies (UPS) systems, Renewable Energy Systems, Distributed Generation and Microgrids, and Industrial Applications and Implementation Issues of the Kalman Filter. He currently chairs of Renewable Energy Systems Technical Committee of IEEE IES.

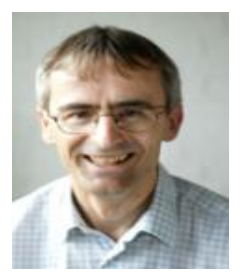

Frede Blaabjerg was employed at ABB-Scandia, Randers, from 1987-1988. During 1988-1992 he was a $\mathrm{PhD}$. student at Aalborg University. He became an Assistant Professor in 1992 at Aalborg University, in 1996 Associate Professor and in 1998 full professor in power electronics and drives the same place. In 2000 he was visiting professor in University of Padova, Italy as well as he became part-time program research leader at Research Center Risoe in wind turbines. In the period of 2006-2010 he was the dean of the faculty of Engineering, Science and Medicine at Aalborg University, Denmark. In 2002 he was visiting professor at Curtin University of Technology, Perth, Australia as well as he became visiting professor for Zhejiang University, China in 2009. His research areas are in power electronics, static power converters, ac drives, switched reluctance drives, modelling, characterization of power semiconductor devices and simulation, power quality, wind turbines, custom power systems and green power inverter. He has been involved many research projects with

the industry. He is the author or co-author of more than 400 publications in his research PersonNamefields including the book "Control in Power Electronics" (Eds. M.P. Kazmierkowski, R. Krishnan, F. Blaabjerg) 2002, Academic Press. Dr. Blaabjerg is a member of the European Power Electronics and Drives Association and the IEEE Industry Applications Society Industrial Drives Committee. He is also a member of the Industry Power Converter Committee and the Power Electronics Devices and Components Committee in the IEEE Industry Application Society. He has been associated editor of the IEEE Transactions on Industry Applications, IEEE Transactions on Power Electronics, Journal of Power Electronics and of the Danish journal Elteknik. Since 2006 he has been Editor in Chief of the IEEE Transactions on Power Electronics as well as Distinguished lecturer for the IEEE Power Electronics Society from 2005 to 2007. It is followed up as Distinguished lecturer for the IEEE Industry Applications Society from 2010 to 2011. He received the 1995 Angelos Award for his contribution in modulation technique and control of electric drives, and an Annual Teacher prize at Aalborg University, also 1995. In 1998 he received the Outstanding Young Power Electronics Engineer Award from the IEEE Power Electronics Society. He has received ten IEEE Prize paper awards during the last ten years (the last in 2008) and another prize paper award at PELINCEC Poland 2005. He received the IEEE Power Electronics Society Distinguished Service Award in 2009 as well as the EPE-PEMC 2010 Council award. In 2002 he received the C.Y. O'Connor fellowship from Perth, Australia, in 2003 the Statoil-prize for his contributions in Power Electronics, in 2004 the Grundfos Prize in acknowledgement of his international scientiPersonNamefic research in power electronics and finally the Director Ib Henriksens Research Prize for the acknowledgment of high level international research in power electronics. In 2010 he received the EPEPEMC Council Award for his contributions in power electronics. He became IEEE Fellow in 2003.

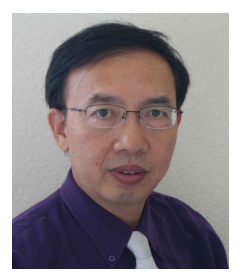

Zhe Chen received the B.Eng. and M.Sc. degrees from Northeast China Institute of Electric Power Engineering, Jilin City, China, and the Ph.D. degree from University of Durham, U.K. Dr Chen is a full Professor with the Department of Energy Technology, Aalborg University, Denmark. He is the leader of Wind Power System Research program at the Department of Energy Technology, Aalborg University. His research areas are power systems, power electronics and electric machines; and his main current research interests are wind energy and modern power systems. He has more than 260 publications in his technical field. Dr Chen is an Associate Editor (Renewable Energy) of the IEEE Transactions on Power Electronics, a Senior Member of IEEE, a Fellow of the Institution of Engineering and Technology (London, U.K.), and a Chartered Engineer in the U.K. 